\title{
Improving Visualization Skills in Engineering Education
}

\author{
Manuel Contero \\ Polytechnic University of Valencia, Spain \\ Pedro Company \\ Jaume I University, Spain \\ José Luis Saorín \\ La Laguna University, Spain \\ Ferran Naya \\ Polytechnic University of Valencia, Spain \\ Julián Conesa \\ Polytechnic University of Cartagena, Spain
}

\author{
We analyze the importance of visualization skills in engineering education, proposing a \\ dual approach, based on computer graphics applications using both Web-based graphic \\ applications and a sketch based modeling system, to improve these capabilities.
}

\begin{abstract}
We analyze the importance of visualization skills in engineering education, proposing a dual approach based on computer graphics applications using both Web-based graphic applications and a sketch based modeling system to improve these capabilities.

With the aim of addressing acquisition of spatial reasoning, we first analyze the importance of spatial abilities in the context of engineering education and the available techniques for evaluating these abilities from a psychological point of view. Then we review some Web resources conceived specially to help students to improve their spatial abilities and present two educational applications, eREFER and eCIGRO, designed with two main objectives: drawing student's attention and fostering two important skills for the future engineers: freehand sketching and understanding the relationship between orthographic and axonometric views. Finally we present a pilot study carried out at La Laguna University using these tools, ending with some conclusions
\end{abstract}

\section{Keywords}

Spatial reasoning, engineering education, sketch based modeling.

Data graphics are usually the best method for analyzing and communicating quantitative information ${ }^{1}$. But, like any means of communication it can deceive if not used correctly ${ }^{2}$. Hence, visualization skills are required to be able to make and read good-quality graphics.

Engineers need general-purpose data graphics, like other groups such as scientists and economists. However, their requirements go far beyond general data graphics up to engineering graphics, which focus on geometrical design, i.e. fixing the geometry that satisfies all the design specifications and communicating it to others. This is currently done through the so-called "design-by-drawing" method, which is currently supported by the body of knowledge known as descriptive geometry and a well-defined set of drawing standards. Commercial 2D CAD applications provide electronic support for it. Nevertheless, since the end of the 80's, 3D CAD applications opened the door to a new "design-by-virtual models" paradigm that is progressively replacing design-by-drawing.

Apprenticeship of engineering graphics is a crucial task in both, design-by-drawing and design-by-virtual models approaches, and it is as complex as all languages. For instance, it includes learning non-formalized rules, like the "simplicity criterion" sometimes expressed in the following terms: "the geometrical shape represented is the simplest one among all those whose projection matches the drawing". Furthermore, non-geometrical and a priori conventions (like graphical semantics and visual stimuli described in Gestalt rules) are implicitly integrated in technical drawings, as they are in all graphical communication ${ }^{2}$. In addition, explicit conventions (standards) have to be considered too. Nowadays, this standardized language learning goal must be complemented by developing a critical skill that was already required but was not as apparent as it is now: the instruction of future engineers is heavily concerned on spatial vision, or acquisition of developed sense of spatial reasoning. And this spatial reasoning that, in the past, was supposed to be indirectly gained while 
learning the standardized language, has now to be explicitly acquired, as it is a critical competence for the users to steer a 3D CAD system.

In the next pages, we first analyze the importance of these abilities in the context of engineering education and the available techniques for evaluating them from a psychological point of view. Then we review some Web resources conceived specially to help students to improve their spatial abilities. Next, we present two educational applications designed with two main objectives: drawing student's attention and fostering two important skills for the future engineers: freehand sketching and understanding the relationship between orthographic and axonometric views. Finally we present a pilot study that has been carried out at La Laguna University, ending with some conclusions.

\section{The importance of visualization skills in engineering education}

Engineering Graphics is not an art but a strict system of signs, and well-reputed works exist to help the reader to know the theoretical basis of both graphics information processing ${ }^{1}$ and graphic communication ${ }^{3}$. The difference is significant as graphics information processing is concerned on the use of graphics to help discovering data relationships, while graphic communication is aimed at easing fast and efficient transmission, and record, of information in general. However, those generic studies do not solve our particular goal, since we shall pay attention not to generic information visualization, but to engineering design information visualization.

In other words, engineers are clearly concerned by data graphics in general, but they are most concerned about the particular kind of engineering drawings. In the chapter "The Tools of Visualization", Ferguson ${ }^{5}$ defines engineering drawings as a means by which a vision in one person's mind might be conveyed by material means -drawings- across space and time to another person's mind. After briefly revisiting the historical evolution of such drawings, he states that they can quickly yield a great deal of information, but only to a reader who knows how to extract it. What is more, he adds that " the best way to learn how to read drawings, and probably the only fully effective way, is to learn how to make drawings".

We can believe these words to be obsolete after the arrival of 3D CAD, however, CAD users essentially manipulate geometry, and visualization governs their interaction with geometry. Hence, they must gain knowledge on both two and three dimensional geometry and spatial reasoning. On the other hand, it is widely recognized that students do not instinctively learn to mentally create and edit graphic information, whilst high visualization ability is the most important prerequisite cognitive process required for a student to be successful in representing three-dimensional objects on two-dimensional media. This is particularly important in teaching future engineers. In a recent special issue on "CAD education" (Computer Aided Design vol. 36 no. 14), Field" finished with a "... call for all CAD-users to obtain a higher developed sense of spatial reasoning", since "... everyone using CAD needs a highly developed sense of spatial reasoning". In our opinion, this is true since design is done essentially in the mind, and drawings are pictorial extensions of the mind.

In sum, one important objective of engineering graphics basic courses, in any engineering discipline, is the development of visualization skills. This capability can be described as the ability to picture three-dimensional shapes in the mind's eye. Acquiring this skill is essential for the future engineer ${ }^{5}$ and much more important than learning procedures and particular "picks and clicks" of specific applications ${ }^{6}$.

We have stated that engineers must learn a graphical language. Graphic (or "non-verbal") languages are those in which transmission of information is based not only on the meaning of a predefined set of signs but also on the spatial relations between all signs; This is to say, the resemblance, order, proportion and neighborhood relations present in every written communication (and necessarily absent in oral communications). Hence, appropriate tools are required to help students to learn to mentally create and edit graphic information.

In parallel, current computers graphical capabilities automate 2D drafting in the design process. Besides, they make it possible the interactive creation and manipulation of 3D virtual models. Furthermore, it is being argued that the next "revolution" will be to make engineering drawings and sketches a universal language for the whole computer-aided design process, through some sort of "artificial perception" system, based on sketch-based modeling and geometrical reconstruction ${ }^{4}$. The utopian objective would be a design system capable of fully integrating the sketch information interactively during the sketch creation and refinement phases; capable of formalizing the non-formalized ideas contained in the sketch; and capable of analyzing and evaluating the provisional model, as well as giving the designer feedback on the performance of the intended idea.

Independently of whether or not we could use systems in the future with the features described previously, sketching remains as a basic tool for speeding up visual problem solving in any field of Engineering, allowing the externalization and representation of design problems. Hence the ability to sketch and perceive three-dimensional shapes in a sketch-based modeling environment is of special interest in the curricula of future engineers, and suitable learning tools are required for that purpose.

So, the need for new tools to support spatial abilities development has been argued. But a last consideration must be taken into account. What user profiles can we find in current freshman engineering courses? Nowadays students are accustomed to managing technologies like Internet, 3D videogames, mobile phones, MP3 players and other technological gadgets. So asking them for classical paper and pencil exercises can be counterproductive, especially if we want to offer voluntary remedial courses to solve their lack in spatial visualization. Our experience with this kind of courses is that it is very difficult to maintain the attention of freshman students, and many times they abandon the course before ending.

Our response to these requirements has been to convert our research tools on sketch-based modeling into educational tools. We believe them to be attractive enough to keep students motivated, especially if they are combined with modern hardware such as TabletPCs.

\section{Web resources to improve visualization skills.}

We can find different approaches in the literature to help students to improve their spatial abilities. So, we can follow strategies based on: traditional paper and pencil, real models, 2D CAD, 3D CAD, 3D animation, computer games and specific computer applications ${ }^{8,9}$ Nowadays, Internet opens new opportunities to provide access to didactic courseware both from school and home. 3D graphic content can be implemented using VRML or the new X3D standard that has a richer set of features than VRML. 2D multimedia authoring tools also are a valuable resource to create compelling contents. Most Web sites with contents related to spatial abilities come from the field of 
psychology, engineering graphics or K-12 education. In many of them, games are used to motivate the students especially the younger ones.

Table A. Some tests for evaluating spatial abilities

\begin{tabular}{|c|c|c|c|c|}
\hline Test & Name & Factor & Authors & Description \\
\hline $\begin{array}{l}\text { Guilford- } \\
\text { Zimmerman } \\
\text { Spatial } \\
\text { Orientation } \\
\text { Test }\end{array}$ & GZSOT & $\mathrm{SO}$ & $\begin{array}{l}\text { Guilford \& } \\
\text { Zimmerman, } 1948\end{array}$ & $\begin{array}{l}\text { Subjects are shown two pictures } \\
\text { with an object in different } \\
\text { spatial orientations, and are } \\
\text { asked to identify in which } \\
\text { direction the object has moved. }\end{array}$ \\
\hline $\begin{array}{l}\text { Perspective- } \\
\text { taking Test }\end{array}$ & & $\mathrm{SO}$ & $\begin{array}{l}\text { Kozhevnikov \& } \\
\text { Hegarty, } 2001\end{array}$ & $\begin{array}{l}\text { Based on asking participants to } \\
\text { imagine an a r antric } \\
\text { perspective transformation }\end{array}$ \\
\hline $\begin{array}{l}\text { Spatial } \\
\text { Relation } \\
\text { subset of the } \\
\text { PMA Test }\end{array}$ & PMA - SR & SR & Thurstone, 1958 & $\begin{array}{l}\text { Based on performing a mental } \\
\text { rotation of two-dimensional } \\
\text { objects }\end{array}$ \\
\hline $\begin{array}{l}\text { Rotation of } \\
\text { Images }\end{array}$ & & SR & $\begin{array}{l}\text { Duerman - Sälde } \\
\text { test battery, } \\
\text { Psykologiförlaget } \\
1971\end{array}$ & $\begin{array}{l}\text { It requires choosing the image } \\
\text { that is identical, unless } \\
\text { rotated, to the one given in the } \\
\text { exercise. }\end{array}$ \\
\hline $\begin{array}{l}\text { Left or Right } \\
\text { Hand } \\
\text { Identification }\end{array}$ & & SR & $\begin{array}{l}\text { Duerman - Sälde } \\
\text { test battery, } \\
\text { Psykologiförlaget } \\
1971\end{array}$ & $\begin{array}{l}\text { It uses images of hands rotated } \\
\text { in different positions. The } \\
\text { subject must determine whether } \\
\text { it corresponds to the left or } \\
\text { right hand. }\end{array}$ \\
\hline $\begin{array}{l}\text { Cards Rotation } \\
\text { Test }\end{array}$ & $\mathrm{CRT}$ & SR & $\begin{array}{l}\text { Ekstrom, French } \\
\text { and Harman, } 1976\end{array}$ & $\begin{array}{l}\text { Based on performing a mental } \\
\text { rotation of two-dimensional } \\
\text { objects }\end{array}$ \\
\hline $\begin{array}{l}\text { Minnesota } \\
\text { Paper Form } \\
\text { Board Test }\end{array}$ & MPFB & $\mathrm{Vz}$ & $\begin{array}{l}\text { Likert \& Quasha, } \\
1941\end{array}$ & $\begin{array}{l}\text { It uses two-dimensional line } \\
\text { drawings of shapes that can be } \\
\text { made out of a set of fragments }\end{array}$ \\
\hline $\begin{array}{l}\text { Differential } \\
\text { Aptitude Test } \\
\text { - Spatial } \\
\text { Relations }\end{array}$ & $\mathrm{DAT}-\mathrm{SR}$ & $\mathrm{Vz}$ & $\begin{array}{l}\text { Bennet, Seasharo } \\
\& \text { Wesman, } 1947\end{array}$ & $\begin{array}{l}\text { The subject must indicate what } \\
\text { an unfolded shape would look } \\
\text { like when folded }\end{array}$ \\
\hline $\begin{array}{l}\text { Paper Folding } \\
\text { and Surface } \\
\text { Development } \\
\text { Test }\end{array}$ & $\begin{array}{l}\mathrm{PFT} \\
\mathrm{SDT}\end{array}$ & $\mathrm{Vz}$ & $\begin{array}{l}\text { Ekstrom, French } \\
\text { \& Harman, } 1976\end{array}$ & $\begin{array}{l}\text { In PFT a paper is folded a } \\
\text { certain number of folds, a hole } \\
\text { is made through the folds then } \\
\text { the paper is unfolded. In SDT } \\
\text { the person must visualize how a } \\
\text { piece of paper can be folded to } \\
\text { form a given object }\end{array}$ \\
\hline $\begin{array}{l}\text { Purdue Spatial } \\
\text { Visualization } \\
\text { Test }\end{array}$ & PSVT & $\mathrm{Vz}$ & Guay, 1977 & $\begin{array}{l}\text { It consists of three parts: } \\
\text { developments, rotations and } \\
\text { views. }\end{array}$ \\
\hline $\begin{array}{l}\text { Mental } \\
\text { Rotation Test }\end{array}$ & MRT & $\mathrm{Vz}$ & $\begin{array}{l}\text { Vanderber and } \\
\text { Kuse, } 1978\end{array}$ & $\begin{array}{l}\text { Requires identifying rotated } \\
\text { versions of three-dimensional } \\
\text { objects composed of cubes. }\end{array}$ \\
\hline
\end{tabular}

\section{How spatial abilities can be measured?}

We can find in the literature several proposals for categorizing spatial abilities. Some researchers have proposed three major spatial factors: spatial relations (SR), in which mental rotations in two dimensions is the common element; spatial orientation (SO), which is related to the ability to imagine the appearance of objects from another perspective (orientation); and spatial visualization $(\mathrm{Vz})$, which is the ability to form a mental image of objects and spatial forms. (Paper-folding or surface-development are some tests that involve visualization). Although some authors don't recognize spatial orientation as a separate factor, recent publications in this area reactivate the discussion promoting its consideration as an independent factor.

On Table A we show some of the most commonly paper-and-pencil tests used in the literature for evaluation of spatial abilities.

At Michigan Technological University we find at: $h t t p: / / w w w . h u . m t u . e d u /$ awysocki/3D/rot1.htm/ one of 10 modules from the published CD-ROM, "Introduction to 3D Spatial Visualization: An Active Approach" by Sorby, Wysocki and Baartmans. Based on Macromedia's Shockwave technology, the application uses colorful shapes rendered to appear truly three dimensional along with interactive animated effects to give students the impression of playing a computer game while honing their visualization skills. 
The University of Massachusetts/Amherst has developed several electronic tutors. They are available at http://mielsvr2.ecs.umass.edu/vsr. The Rotation Tutor is intended to extend students' ability of reasoning on 3D rotation. The Engineering Drawing Tutor supports the student in drawing either an orthographic or isometric view of a part. It is intended to help students in the process of building a mental image of an object from its orthographic projections and vice-versa.

"Visualization Assessment and Training" site at Pennsylvania State University is dedicated to the understanding and improvement of spatial visualization skills. There are three interactive activities on this site: Rotating Blocks, Paper Folding and Water Level. These are well known tasks from research on spatial cognition and are available at: http://viz.bd.psu.edu/viz/

"Illuminations" site is a partnership between the US National Council of Teachers of Mathematics and MarcoPolo consortium. Under the Tools link at http://illuminations.nctm.org there are many interesting applets, for example Isometric, is an interactive applet which creates dynamic drawings on isometric dot paper. Users can draw figures using edges, faces, or cubes and then shift, rotate, color, decompose, and view them in 3D or 2D.

Interesting resources with multimedia content awarded by the Spanish Ministry of Education (in Spanish) are offered at: http://www.cnice.mecd.es/recursos/bachillerato/dibujo/tecnico. It contains multimedia applications on technical drawing concepts for high

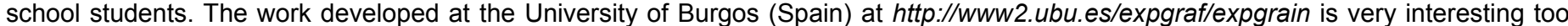
because of its university level contents.

University of Texas-Pan American hosts an interesting web site with links to web-based games that reinforce significant Engineering Graphics concepts, and some interactive web-based quizzes. You can find these at $h t t p: / / c r o w n . p a n a m . e d u / E G / g a m e s$.

"Spatial Intelligence" Web site at University of Limerick in Ireland provides 75 interactive exercises to help students to develop their spatial abilities. Animation is used to clarify solutions. Some exercises at $h$ ttp://www.ul.ie/ mearsa/9519211 use VRML virtual environments to further enhance spatial functioning and enrich spatial understanding.

\section{Sketch Based Modeling in an Educational Context}

In the last years the REGEO research group (http://www.tec.uji.es/d/regeo) has been working in both on-line and batch computeraided generation of 3D models from 2D freehand sketches. Combining these elements with our experience in teaching traditional Engineering Graphics, has led us to develop some "special" learning support tools for developing spatial abilities in engineering design. We have tried to provide our students with attractive applications that combine and develop three important elements for the future engineer: spatial visualization, freehand sketching and standardized view generation. These tools are based on two previous research sketchbased modeling applications called REFER ${ }^{7}$ and CIGRO (ref. 4 on sidebar on Sketch Based Modeling) that have been adapted for educational purposes. We chose these systems because we can modify and adjust them to improve the user experience in different educational contexts as remedial courses, regular engineering graphics courses and conceptual design tasks.

\section{Calligraphic Interfaces and Sketch Based Modeling.}

Despite great evolution in Computer Aided Design systems since the end of the $60 \mathrm{~s}$, Graphical User Interfaces (GUI) have not evolved from the WIMP (Window, Icon, Menu, Pointing device) paradigm. Nowadays, new hardware devices such as Tablet-PCs open new opportunities to experiment with different user interfaces using a digitizing tablet and a pen. The term "calligraphic interface" (see Computers \& Graphics vol. 24, special issue on Calligraphic Interfaces) covers a new kind of user interface that relies on interactive input of drawings as vector information (pen-strokes) and gestures, possibly coupled with other interaction modalities. Aided with those tools, sketch-based modeling applications aim at providing an intelligent and interactive modeling support to visual thinking in the conceptual design stage of product development.

Surveying the literature we identify two main approaches to sketch-based modeling. One method, gestural modeling, relies on gesture alphabets as commands for generating objects from sketches. SKETCH is a classical reference in this field. It is basically aimed at architectural forms, in which the geometric model is entered by a sequence of gestures according to a set of conventions, regarding the order in which points and lines are entered as well as their spatial relations. Teddy, allows free form surface modeling using a very simple interface of sketched curves, pockets and extrusions. Users draw silhouettes using a series of pen strokes. The system automatically proposes a surface using a polygonal mesh whose projection matches the object contour. Nowadays Teddy is both a PC package software and a PlayStation2 game in Japan.

The second approach, reconstruction-based modeling, uses techniques from the field of computer vision, to reconstruct geometric objects from sketches that depict their two dimensional projection.

Examples of this approach are Digital $\mathrm{Clay}^{3}$ and $\mathrm{CIGRO}^{4}$. Both support basic polyhedral objects and implement calligraphic interfaces for input. Digital Clay uses a reconstruction engine that uses Huffman-Clowes algorithms to derive three-dimensional geometry, and CIGRO is based on an axonometric inflation engine to build the three-dimensional geometry. Finally, a third "hybrid" approach combines the two approaches mentioned, to input models through a combination of gesture commands and reconstruction, as is the case of GEGROSS $^{5}$ and SMARTPAPER ${ }^{6}$. 


\section{References}

1. R.C Zeleznik, K.P. Herndon, and J.F. Hughes, "SKETCH: An Interface for Sketching 3D Scenes". Proc. SIGGRAPH'96 Conf., ACM Press, NY, 1996, pp. 163-170.

2. T. Igarashi, S. Matsuoka, and H. Tanaka, "Teddy: A Sketching Interface for 3D Freeform Design". Proc. SIGGRAPH'99 Conf., ACM Press, NY, 1999, pp. 409-416.

3. E. Schweikardt and M.D. Gross, "Digital Clay: Deriving Digital Models from Freehand Sketches". Autom. in Construction, vol. 9, 2000, pp. 107-115.

4. M. Contero, F. Naya, J. Jorge, and J. Conesa, "CIGRO: a Minimal Instruction Set Calligraphic Interface for Sketch-based Modeling". Lecture Notes in Computer Science, vol. 2669, 2003, pp. 549-558.

5. F. Naya, N. Aleixos, M. Contero, and J. Jorge, Parametric Freehand Sketches. Lecture Notes in Computer Science, vol. 3044, 2004, pp. 114-120.

6. A. Shesh and B. Chen, "SMARTPAPER: An Interactive and User Friendly Sketching System. Computer Graphics Forum vol. 23, no. 3, 2004, pp. 301-310.

These educational versions called eREFER ${ }^{10}$ and eCIGRO are aimed at aiding the learning of orthographic views process. It is intended to drive the student at establishing correlations between orthographic views (automatically generated by the application) and the sketched axonometric representation of the part he or she has drawn. Moreover, the possibility to change from first to third angle projections, and the possibility to activate or deactivate the visualization of hidden lines and the reference system increase the spatial vision capability by enforcing the relation between axonometric and orthographic views (figure 1 center). Besides, the application emphasizes some visualization skills like the discrimination between "Necker reversals" inherent to wireframe representations but clearly perceived in B-rep models (figure 1 below).

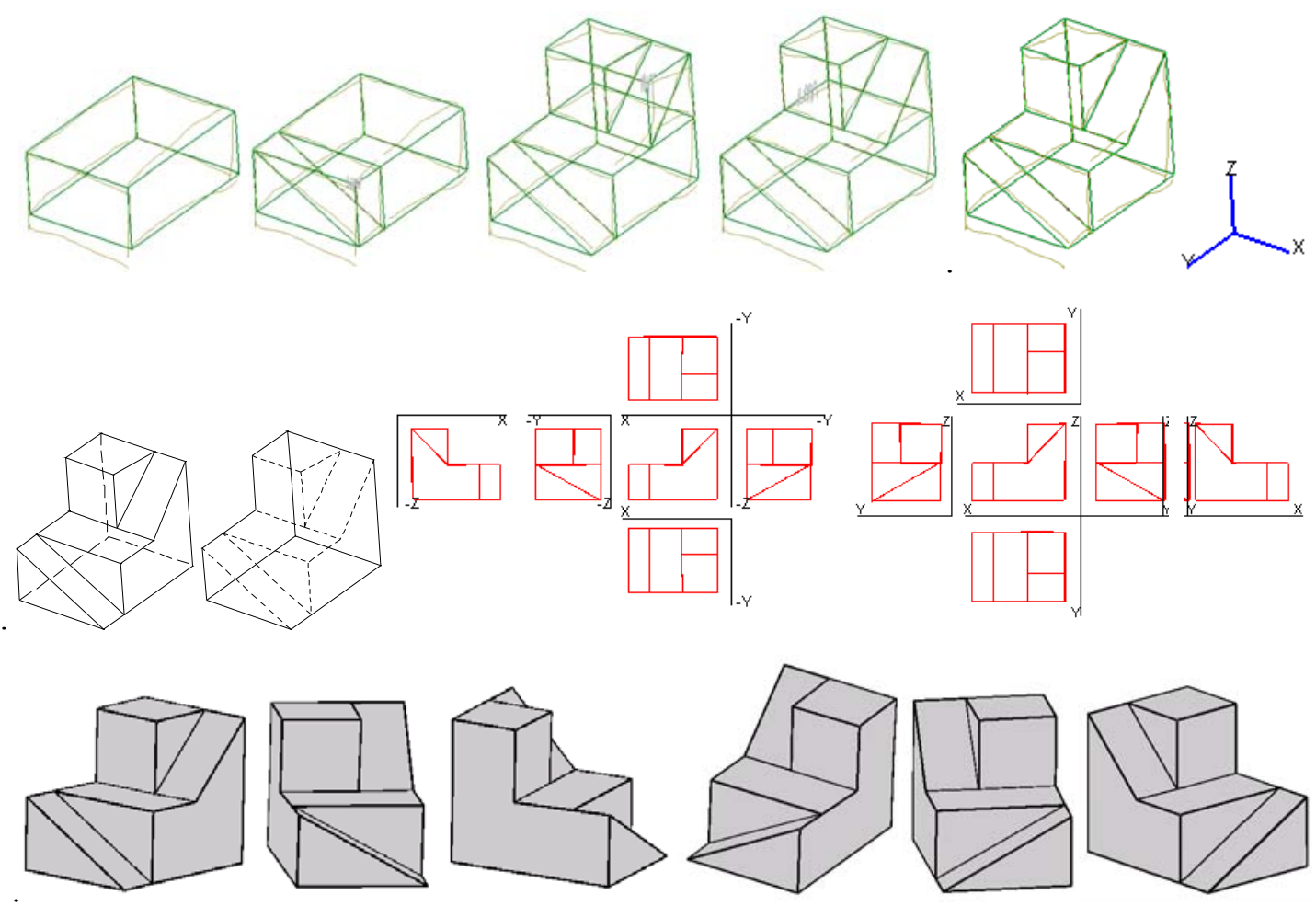

1. Snapshots of interactive input sequence in eREFER. To note the construction lines, that are removed latter (above). Hidden lines of the two 3D "Necker reversal" models, and third and first angle orthographic views for the first one (middle). Snapshots of interactive rotation of the two 3D "Necker reversal" models (below). 


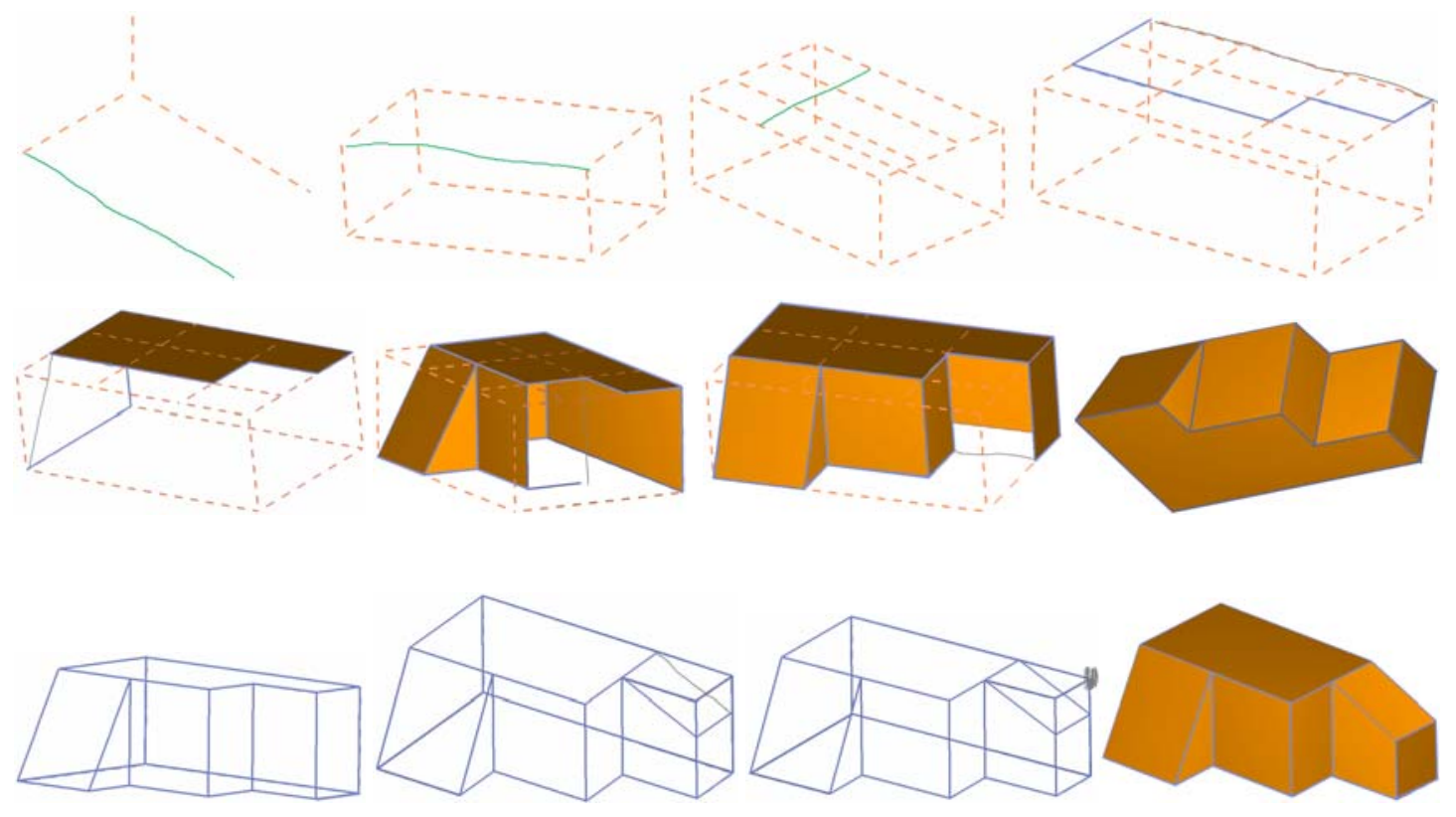

2. Snapshots of interactive input sequence in eCIGRO. If user draws making low pressure, green color is used to represent raw strokes before processing, and then they are beautified in orange dashed auxiliary lines, that can be used for snapping purposes. If user draws making high pressure, gray color is used to represent raw strokes before processing, and then they are beautified in blue lines, representing real geometry. The user can change the point of view and zoom during the sketching process, as can be seen in the sequence, and continue drawing. Third and first angle orthographic views can be generated automatically as in eREFER.

Sketches of pseudo-axonometric representations of rectangular polyhedral shapes are the inputs in both applications, i.e. polyhedral models in which edges converge at $90^{\circ}$, as do all the faces that share an edge. We refer to such orthogonal or rectangular polyhedrons as "normalons". In fact these systems are able to manage "quasi-normalons": polyhedral shapes in which no vertex is lost after removing non-orthogonal edges (see the part in figure 1). Sketches of many "skeletons" or "control structures" used to model complex mechanical parts in 3D CAD and many sketches of architectural buildings belong to this category. All of them are easily reconstructed by our applications.

eREFER operates in batch mode: whenever the user finishes the sketch, he or she may ask the system to "reconstruct" the 3D model represented by the drawing by pushing a button. It implements a dual window scheme of visualization: One window for sketching and the other for visualization. In eCIGRO we use a single 2D-3D window, and the reconstruction process is performed online. As the user refines the geometry, the system updates the 3D model. Students can sketch and immediately switch the point of view and see the corresponding 3D model, and continue to sketch from this new point of view (as shown in the drawing sequence of figure 2).

Reconstruction-based applications usually include a preliminary "2D reconstruction" or beautification stage, where the input sketch is adjusted before proceeding with the 3D reconstruction. eREFER, as a batch reconstructor, is able to perform a sophisticated beautification process. To do that, the input drawing is first repaired through a tiding up process which converts the sketch into a line drawing and provides a detailed analysis of it, to discover some design intents that are difficult to detect whilst drawing is in progress (edge connections, main axis, faces, hidden edges, symmetry planes, etc.). Next, an "axonometric inflation" is done to obtain the $3 \mathrm{D}$ model.

On the other hand, eCIGRO performs a real time conversion from sketch into line drawing, in order to provide an adequate database for the axonometric inflation engine. As the user sketches a line the application adjusts it using the following drawing aids: automatic line slope adjustment, vertex point snap and vertex on line snap. The first drawing aid consists of checking whether the new line is parallel to any of the principal axes of the sketch or other line by considering a slope tolerance. In such case, one or both endpoints are adjusted so that the line results precisely parallel. The second analysis looks for new vertices proximity to previous ones, taking into account a vertex proximity tolerance. If new vertices fall into the tolerance region of previous vertices then they are snapped to the closest previous vertex. For endpoints of new lines which do not lie close to previous vertices, the system analyzes whether they are close to an existing edge, taking into account a given edge proximity tolerance. If several edges match this criterion, then the edge that lies closest to the given endpoint is selected. Snap tolerances exist to provide control to soften the beautification action.

eREFER, as an offline reconstructor, has some advantage with respect to eCIGRO in detecting complex geometric relationships. In this sense eREFER includes a module to detect bilateral symmetry planes before the 3D model is obtained. Hence, this capability can be used to question the student about the symmetry features of a part ${ }^{10}$.

Both applications implement a very simple calligraphic interface for sketch input. eREFER uses only two gestures: draw edge and remove edge. eCIGRO adds a third gesture for defining auxiliary edges. This last feature represents the most important difference between the two applications: eCIGRO supports both real geometry and auxiliary lines. This emulates an extended practice for making sketches. First, the user draws a set of auxiliary lines to define the main geometric features of the object and then, using this skeleton as a drawing 
template, the designer refines the sketch by drawing "thick" lines over the previous template. Simply increasing the pencil pressure on the tablet simulates thickness, i.e., by taking into account the pressure made on the pencil; eCIGRO distinguishes auxiliary lines (lighter and thinner as less pressure is applied) from real geometry lines (darker strokes drawn making higher pressure on the pen).

\section{A Pilot Study.}

Most published experiences related to spatial abilities improvement are based not on the development of new tools but on analyzing the impact in the development of students' spatial skills of different contents of the Engineering Graphics discipline ${ }^{12}$; as Descriptive Geometry, Technical Drawings, and, sometimes Solid Modeling ${ }^{11}$. In addition, they are mainly based on classic paper and pencil exercises, unless sometimes commercial CAD applications are used too.

In order to prepare an extensive study to analyze the impact of both visualization oriented Internet graphic applications and the use of software adapted specifically to foster spatial visualization as the eREFER and eCIGRO applications described before, during the autumn of 2004 a pilot study was carried out at La Laguna University. Its main objective was to serve as a test bed to experiment with different contents to define the structure of remedial courses to improve the spatial visualization proficiency of engineering freshman students.

Our hypothesis was that both Web graphic applications and sketch based modeling tools can be as effective as conventional approaches based on paper and pencil exercises. Another important point was finding the most attractive features of the Web sites used in this pilot study and the eCIGRO sketching application.

We selected the Mental Rotation Test (MRT) and the Spatial Relations subset of the Differential Aptitude Test (DAT-SR) to detect those students with poorer spatial abilities, and to evaluate the outcomes of the three remedial courses we designed. Up to 461 students were "pre-tested", achieving a mean score of 16.75 in MRT and 42.96 in DAT-SR. The 78 worst scored students were selected for attending an intensive remedial course, although only 52 of them completed it. The mean MRT score for these students was 9.04 and 31.44 for DAT-SR.

Three six-hour remedial courses (coded as A, B and C) were designed and arranged in three two-hour sessions. Due to their short duration, their main objective was to improve the spatial skills of the students till the minimum level required to follow a basic Engineering Graphics course normally. To avoid interferences from regular lectureship, they were run during the first week of the semester, and the lecture contents were rearranged to prevent any similitude with tests. Once the remedial course was finished, the students were tested again ("post-tested") using the same type of tests as before (MRT and DAT-SR).

"A type" remedial course was exclusively based on paper and pencil exercises, putting the emphasis in using standardized view problems to improve spatial vision. Exercises were arranged in increasing order of difficulty: face identification in the orthographic projections of an object represented by an axonometric view, face identification in the axonometric view of an object represented by its standardized views, location of views, recount exercises, orthographic view generation from an objects perspective, and axonometric view construction from standardized views.

"B type" course was Web-based. Most exercises were extracted from the Engineering Graphics Department web site at University of Burgos, available at $h t t p: / / w w w 2$.ubu.es/expgraf/expgrain /visualizacion3d. This site uses VRML models to help students to complete visualization exercises.

"C type" course was mostly structured around the eCIGRO application. As an introduction to axonometric drawing, students were initiated in the "Isometric" applet, available at the Illuminations site in http://illuminations.nctm.org. A6 graphics tablets (Wacom Volito) were made available for students to sketch axonometric views of objects represented by standardized views or axonometric perspectives.

In table 1 we show the pre and post scores obtained by students ( $n$ represents the number of students that completed the whole remedial course).

\begin{tabular}{|c|c|c|c|c|}
\hline \multirow[b]{2}{*}{ Group } & \multicolumn{2}{|c|}{$\begin{array}{c}\text { MRT } \\
\text { All students mean } \\
\text { score: } 16.75\end{array}$} & \multicolumn{2}{|c|}{$\begin{array}{c}\text { DAT-SR } \\
\text { All students mean } \\
\text { score: } 42.96\end{array}$} \\
\hline & $\begin{array}{l}\text { Pre-Test } \\
\text { (St. Dev.) }\end{array}$ & $\begin{array}{l}\text { Post-Test } \\
\text { (St. Dev.) }\end{array}$ & $\begin{array}{l}\text { Pre-Test } \\
\text { (St. Dev.) }\end{array}$ & $\begin{array}{l}\text { Post-Test } \\
\text { (St. Dev.) }\end{array}$ \\
\hline$\underset{n=17}{\mathrm{~A}}$ & $\begin{array}{c}8,18 \\
(4,60)\end{array}$ & $\begin{array}{l}13,53 \\
(6,12)\end{array}$ & $\begin{array}{l}28,47 \\
(8,57)\end{array}$ & $\begin{array}{c}39,35 \\
(10,09)\end{array}$ \\
\hline$\underset{n=15}{\mathrm{~B}}$ & $\begin{array}{c}9,60 \\
(4,46)\end{array}$ & $\begin{array}{l}13,27 \\
(4,80)\end{array}$ & $\begin{array}{l}30,53 \\
(5,40)\end{array}$ & $\begin{array}{l}35,67 \\
(5,60)\end{array}$ \\
\hline $\begin{array}{c}\mathrm{C} \\
n=20\end{array}$ & $\begin{array}{c}7,85 \\
(3,56)\end{array}$ & $\begin{array}{l}12,05 \\
(5,33)\end{array}$ & $\begin{array}{l}33,00 \\
(6,26)\end{array}$ & $\begin{array}{l}40,40 \\
(8,92)\end{array}$ \\
\hline
\end{tabular}

For the statistical analysis we used a Student's $t$-test taking as the null hypothesis $\left(\mathrm{H}_{0}\right)$ that abilities of spatial visualization mean values have not varied after courses have taken place. The t-Student for paired series was applied and $p$ values representing the probability of the hypothesis being true were obtained. As can be seen in table 2, the level of significance is always minor than $1 \%$, but for MRT for group $B$, where the level is minor than $5 \%$.

Table 2. Level of significance for three courses

\begin{tabular}{|c|c|c|}
\hline Group & MRT & DAT-SR \\
\hline A & $\mathrm{P}=1.15 \mathrm{E}-4<0,01$ & $\mathrm{P}=4 \mathrm{E}-7<0,01$ \\
\hline $\mathrm{B}$ & $\mathrm{P}=0,043<0,05$ & $\mathrm{P}=0,002<0,01$ \\
\hline C & $\mathrm{P}=5.05 \mathrm{E}-4<0,01$ & $\mathrm{P}=2.18 \mathrm{E}-5<0,01$ \\
\hline
\end{tabular}


Hence the null hypothesis is rejected in all cases, and we can conclude, with a level of significance higher than $99 \%$ (95\% for group's B MRT) that the average of groups under study did experiment a positive variation. In other words, the remedial courses had a measurable and positive impact on the spatial ability of students in all three cases, measured by both MRT and DAT tests.

Due to the voluntary nature of these remedial courses, the students' level of satisfaction was another interesting output. We measured it through an experience carried out at the Polytechnic University of Valencia, which has reported interesting conclusions about what are the most appealing contents in this kind of courses. Clearly "C-type" courses organized around sketch-based modeling were the best appreciated by students, followed by "B-type", and at some distance "A-type".

It is important to note that the use of conventional graphic tablets implies a limitation in the effectiveness of "C-type" courses. Students that have their first contact with these devices during the course are not accustomed to drawing on the tablet and seeing the results on the screen. In our opinion, Tablet-PCs or LCD graphic tablets provide a more natural experience, with the only inconvenience of cost.

\section{Conclusions}

The pilot study confirms that intensive remedial courses are a viable strategy for providing students with a minimum level on their spatial abilities. Use of Web resources and sketch-based modeling tools are valid strategies, alternative to classical paper and pencil exercises.

Sketch-based applications look specially promising since they have a side effect in improving the ability of sketching, while visual thinking is being reinforced as well. They have received the best assessment by students that are surprised by the capability of the system in transforming a 2D sketch in a 3D model. Exploiting this appeal can be very productive from an educational point of view.

The pilot study presented in this paper will serve as a guide for a more ambitious study to be performed at the Polytechnic University of Valencia and Cartagena, Jaume I and La Laguna universities. Final versions of eCIGRO and eREFER applications will be available at http://www.tec.uji.es/d/regeo.

\section{Acknowledgements}

This work has been supported by the Spanish Ministry of Science and Education and the European Union (Project DPI2004-01373). Also, this work was partially supported by Fundació Caixa Castelló-Bancaixa under the Universitat Jaume I program for Research Promotion (Project P1-1B2004-02, titled "Gestural interface for the introduction of variational-parametric sketches and for the definition of assembly conditions in the computer-aided design of industial products").

\section{References}

1. J. Bertin, Graphics and Graphic Information Processing. Walter De Gruyter \& Co, Berlin, 1981

2. G. Bertoline, E. Wiebe, C. Miller and L. Nasman, Fundamentals of Graphics Communication, $3^{\text {rd }}$ ed., McGraw-Hill, 2003.

3. E.R. Tufte, The Visual Display of Quantitative Information. Graphic Press, Cheshire, Conn., 1992.

4. P. Company, A. Piquer A. and M. Contero, "On the Evolution of Geometrical Reconstruction as a Core Technology to Sketch-Based Modeling. Proceedings of the Eurographics Workshop on Sketch-Based Interfaces and Modeling (SBM04), Eurographics Association, 2004, pp. 97-106.

5. E.S. Ferguson, Engineering and the Mind's Eye, MIT Press, Cambridge, Mass., 1992.

6. D.A. Field, "Education and Training for CAD in the Auto-industry". Computer-Aided Design, vol. 36, no. 14, 2004, pp. 1431-1437.

7. P. Company, M. Contero, J. Conesa, and A. Piquer, "An Optimisation-based Reconstruction Engine for 3D Modelling by Sketching. Computers \& Graphics, vol. 28, no. 6, 2004, pp. 955-979.

8. Y.S. Kim, J.S. Lim, and J. Dicker, "Visual and Geometric Reasoning for Introductory Figural Space Design". Advances in Engineering Software, vol. 34, 2003, pp. 1-16.

9. C. Hubbard, O.J. Mengshoel, C. Moon, and Y.S. Kim, "Visual Reasoning Instructional Software System". Computers and Education, vol. 28, no. 4, 1997, pp. 237-250

10. P. Company, M. Contero, A. Piquer, N. Aleixos, J. Conesa, and F. Naya, "Educational Software for Teaching Drawing-based Conceptual Design Skills. Computer Applications in Engineering Education, vol. 12, no. 4, 2004, pp. 257-268.

11. R. Devon, R.S. Engel, R.J. Foster, D. Sathianathan and F.F.W. Turner, "The Effect of Solid Modeling Software on 3-D Visualization Skills", Engineering Design Graphics Journal, vol. 58, no. 2, 1994, pp. 4-11.

12. C. Leopold, R.A. Gorska and S.A. Sorby, "International Experiences in Developing the Spatial visualization Abilities of Engineering Students", Journal for Geometry and Graphics, vol. 5, no. 1, 2001, pp. 81-91. 